\title{
Epigrafía funeraria nazarí: el epitafio de al-Yanaštī (835/1436)
}

\author{
Funerary epigraphy of the nasrid kingdom: the al-Yanaštī gravestone \\ (835/1436)
}

Carmen Barceló*

\begin{abstract}
RESUMEN
Este artículo analiza la epigrafía funeraria nazarí y establece la estructura de los epitafios andalusíes conservados datables entre los siglos XIII y XV. Se estudia también una pieza arqueológica cuyo exacto origen se desconoce, aunque se puede deducir que apareció en la región de Granada. La piedra se usó en el siglo XV para grabar el epitafio de un hombre musulmán cuyo texto se conserva completo en siete líneas de escritura árabe cursiva en relieve. Formó parte de la colección del Duque de Santa Lucía y hoy integra el lapidario árabe del Museo Arqueológico Nacional (No. Inv. 1962/34/15).
\end{abstract}

Palabras clave: Epigrafía árabe. Edad Media. alAndalus. Reino Nazarí. Epitafio (835/1436).

La letra cursiva andalusí guarda su mejor expresión en tierras granadinas, donde sus manifestaciones en los yesos de la Alhambra, en piezas muebles de cerámica, madera o metal y en otros restos conservados en diversos edificios del antiguo reino nazarí han generado abundantes estudios. Sin embargo no se han llegado a caracterizar los cambios producidos a través de los siglos en la escritura artística, monumental y documental del sultanato andalusí que sobrevivió en el sureste peninsular, ni la evolución de sus letras; puede decirse que apenas se cuenta con información cronológica fehaciente ni con una muestra de alfabetos que permita determinar la huella epigráfica dejada por el estilo cursivo en la historia de la Epigrafía de al-Andalus.

El espacio de un artículo de revista resulta insuficiente para mostrar los cambios que se

\begin{abstract}
This article analyzes the Nasrid funerary epigraphy and establishes the structure of the epitaphs preserved of Al-Andalus from 13th to 15th centuries. This article also studies an archaeological piece. Its exact origin is unknown, though it supposedly appeared in the region of Granada (Spain). The stone was used in the 15th century to engrave the epitaph of a Muslim man. The text of the epitaph is preserved complete and consists of seven lines of Arabic script in relief. It is part of the Arabic lapidary of the MAN (N. Inv. 1962/34/15) and formed part of the Duke of Santa Lucia collection.
\end{abstract}

Key words: Arabic Epigraphy. Middle Ages. alAndalus. The Nasrid Kingdom. Epitaph (835/1436).

produjeron en el uso de la escritura monumental de los poderosos, aunque permite colmar el vacío que existe sobre los usos del formulismo empleado en el protocolo de los epitafios nazaríes. Los estudios realizados hasta ahora en este campo nos sitúan ya lejos de la subjetiva apreciación de que las estelas andalusíes presentan frases hechas "independientemente del lugar y de la época, fórmulas piadosas repetidas y citas coránicas sin la bella y elegante concisión ni el cálido sentimiento humano de algunos epitafios romanos" (TORRES BALBÁS, 1957: p. 158).

La estela que aquí analizaré se conoce a través de un breve informe del arabista Miguel Asín Palacios (1871-1944), para quien el finado y su padre habrían sido oriundos de El Puig, en tierra valenciana. Aunque no sea totalmente inédita, la pieza podrá ayudar a mejorar el

* Departamento de Filología Catalana. Facultad de Filología, Traducción y Comunicación. Universidad de Valencia. 
conocimiento de la estructura de los textos funerarios del último período político de alAndalus (siglos XIII al XV) pendiente desde hace un cuarto de siglo.

\section{TUMBAS Y EPITAFIOS}

Abordaré de forma somera los usos que los andalusíes y los habitantes del sureste peninsular siguieron en el enterramiento. La aplicación más estricta de la ley islámica manda que el cadáver se debe enterrar en tierra virgen y la tumba debe carecer de adornos. El registro arqueológico muestra que este principio se cumplió en más del 90\% de las sepulturas estudiadas; no obstante, además de esta fosa simple mayoritaria hubo otras maneras de cubrir los restos mortuorios (MARTíNEZ NÚÑEZ, 1994).

Las excavaciones han documentado la variedad de cubriciones en un territorio cuya extensión fluctuó -como sabemos-desde el mayor espacio andalusí en el siglo VIII al más menguado del reino nazarí al final del siglo XV. Se han evidenciado multitud de variantes, según zonas geográficas y épocas: desde tumbas cubiertas con cantos de río, hasta otras tapadas con tejas o con ladrillos; en otras el armazón se delimitó también con lajas de piedra o de ladrillos; a veces sobre la estructura se construía otra de mampuesto; en ocasiones se levantaban muros de piedra; en algunas se colocaba sobre el túmulo o a ras del suelo una forma de ataúd de piedra, con un montículo; e incluso se documentan enterramientos cerrados con losas por los cuatro lados y cubiertos por otra lápida a modo de cistas (W.AA., 1995).

Para señalar el espacio ocupado por la cabeza del cadáver, sobre estas estructuras o sobre la tierra yerma podía colocarse un testigo de piedra (a veces dos o más) de formato rectangular, que fue una de las hechuras más habituales en al-Andalus en todos los tiempos. Esta pieza, que podía recoger a modo de estela un escrito con letras de estilo cúfico o cursivo, recibió en Egipto el nombre árabe de balāt, en al-Andalus se llamó lawh (o rujām si era de mármol) y en el norte de África y Oriente šāhid y mušhad (BARCELÓ, 1998: pp. 57-63).

A partir del siglo XII muchas sepulturas en zonas orientales de la Península, desde Tarragona a Málaga, se cubren con una pieza sepulcral más compleja. Se trata de un tipo de túmulo de sección triangular, achaflanado por ambos extremos. Se hallan a menudo sin escritura; pero no faltan los que conservan textos grabados en caligrafía cúfica o nasjí, a veces con una escueta cita coránica, una poesía elegíaca o el propio epitafio. En al-Andalus se llamó sanām 'espinazo', 'cerro' (BARCELÓ, 1998: pp. 63-65), aunque hace tiempo que se ha impuesto maqabriya, del término dialectal marroquí para 'piedra sepulcral' difundido por un clásico trabajo sobre cementerios (TORRES BALBÁS, 1957). Restos de piedra arenisca de la Malahá, de estas y otras estelas de forma alargada anepigráficas o con inscripción, aparecen en la ciudad de Granada desde hace tiempo (GARCÍA LARIOS, 2006); algunas posiblemente fueran simple poste para delimitar la tumba (TORRES BALBÁS, 1957: p. 154; MANCILLA CABELLO, ROMÁN PUNZÓN, 2010).

Postes y túmulos de sección cuadrangular y remate circular-incluso algunos de ellos con una o dos mortajas o hendiduras de enlace en dos de sus caras- guarda el Museo de Ávila que se han hallado en el cementerio mudéjar (con unos 3.000 enterramientos) y que en 2004 alcanzaban ya el número de 113. Una de las dos piezas sin fecha que estuvo en la iglesia de Santiago lleva grabado en árabe un texto coránico (Q XXVIII, 88); del epitafio de un hombre fallecido en 1492 que se desarrollaba en varias piezas la Catedral guarda un túmulo y el museo abulense conserva el resto (JIMÉNEZ GADEA 2002 y 2009: pp. 229 nota 24 y p. 254).

En el período entre el siglo XIII y XV aparece otro elemento para marcar la tumba: una piedra rectangular, casi un paralelepípedo, a veces cuadrada y en otras ocasiones con el lado superior redondeado; la mayor parte se decora con ajimez y arcos lobulados o de herradura tallados con escaso resalte y algunas tienen variadas formas geométricas y florales. Se han hallado reutilizadas en la 
Alhambra (VÍLCHEZ VÍLCHEZ, 1988); y sin contar la parte que se hundía en tierra, las más grandes suelen tener medio metro de altura por unos 25 o 30 de anchura o de diámetro. Se han recogido tanto en tierras nazaríes (Algeciras, Granada, Málaga, Ronda) como mudéjares (Ascó, Vinebre; sin decoración en Benilloba, Artana o Moura). Un friso colocado en la parte superior o inferior de algunas de estas estelas únicamente lleva una breve afirmación de fe, sola o tal vez combinada o completada con otras piedras parecidas, como las publicadas de Montefrío, Ronda, Málaga y Moura (lā ilāh illā Allāh; șallà Allāh 'alà Muhammad; Muhammad rasūl Allāh; lā gāliba illā Allāh; wa-lā hawl wa la quwwa illā bi-llāh).

No olvidemos que este tipo de señalización de tumba, con perfil de arco de herradura sin enmarque rectangular, tiene una forma análoga -como ya señalara Guillén Robles (1880: p. 538, 1957: p. 336)- a las piezas discoidales de los siglos XII al XIV usadas en los reinos cristianos peninsulares (CASA, JUSUE, MENCHON, 1989; PAVÓN, 1993: p. 19), lo que podría llevar a replantearse la hipótesis de la única génesis meriní. El formato almendrado, además de hallarse en multitud de epitafios del norte de África (desde Túnez a Marruecos), es el perfil de algunas estelas tumulares de época almohade halladas en Mallorca (ROSSELLÓBORDOY, 1975: n 17-19, 21). Piezas del período medieval parecidas a éstas se han hallado en Marruecos, donde han perdurado hasta el siglo XIX de la costa norte a la capital misma del imperio tanto en piedra arenisca como en mármol (MEUNIÉ, TERRASSE, DEVERDUN, 1957: f. 85; BOURRILLY, LAOUST, 1927).

Otra novedad se detecta en esta misma época: el uso de piezas cerámicas para delimitar la fosa. Se considera que empezaron a utilizarse a partir del siglo XIV (FERRANDIS, 1925: p. 179). Aunque no es tarea fácil poder determinar el origen de esta variedad, la primera documentación en suelo andalusí podría ser ahora el siglo XIII según descubren fragmentos hallados en Algeciras o en Málaga, todos con cubierta vítrea de color verde y algunos con letreros de escritura cúfica (TOMASSETTI et alii, 2005; GUILLÉN ROBLES 1880: p. 538 y 1957: p.
335; FERNÁNDEZ GUIRADO, 1993). Además de túmulos triangulares y estelas rectangulares (GONZÁLEZ MARTÍ, 1952; MARTÍNEZ NÚÑEZ, 1995), hay ladrillos decorados, vidriados en dos caras y el canto superior, que se integran a otro de pie rectangular unido a un disco o almendra, a veces con dos apéndices divergentes en la parte superior. Los ladrillos, hincados en el suelo a modo de pequeñas estelas, señalizaban la tumba.

Hace tiempo que estas piezas, halladas de manera fortuita fuera de excavaciones científicas, ingresan en el mercado anticuario y se dispersan entre los coleccionistas porque, impresas bajo el vedrío o pintadas en cobalto, verde o manganeso sobre fondo blanco, la pieza cerámica puede llevar palabras o frases habituales en otros objetos, en los que tales expresiones se consideran profilácticas: al-yumn al-dā'im; al-'izz al-qā'im; al-mulk li-llāh; al-'āfiya; wa-l-yumn wa-l-iqbāl; al-baraka li-llāh; al-gibța li-llāh; al-gibta al-muttașila li-llāh; yā tiquatì yā amalì (GONZÁLEZ MARTí, 1952; ACIÉN, 1978; ACIÉN, MARTÍNEZ NÚÑEZ, 1982; MARTÍNEZ CAVIRÓ, 1982; MARTÍNEZ NÚÑEZ, 1995; TORREMOCHA, MARTÍNEZ, 2004). En alguna otra se cita $Q$ XII, 64 (fa-Allāh jayr hāfizan wa-huwa arham al-rāhiminn), pasaje empleado por almohades y nazaríes y también en el mudéjar cristiano, como el Palacio de Pedro IV en Sevilla.

Además de Málaga y Granada, en donde han aparecido piezas cerámicas pintadas en cobalto o dorado (ACIÉN, MARTÍNEZ NÚÑEZ, 1982; GONZÁLEZ MARTÍ, 1952: 2, p. 206; MARTíNEZ CAVIRÓ 1982, 1991, 2010), otras vidriadas se descubren en morerías mudéjares, tanto en la actual provincia andaluza de Huelva como en Levante, en las ciudades de Valencia, Manises (GONZÁLEZ MARTÍ, 1952: 2, pp. 208-212, fs. 262-272), Cartagena o Buñol; el musulmán bajo dominio cristiano, además del ladrillo y la estela redonda, usó otros tipos cerámicos: la loseta o azulejo, la escudilla, y el plato, como en la soriana Ágreda y en diferentes aljamas valencianas (CASA, DOMENECH, 1984; GONZÁLEZ MARTí, 1952: 1, pp. 298-301). En las tumbas del cementerio morisco de la localidad de Petrés (Valencia), dibujadas en 1563 
por el pintor belga Anton Van den Wyngaerde, se pueden observar disposiciones similares a las descubiertas en otras zonas peninsulares (BARCELÓ, 1998: fg. 4).

En cuanto a la estela rectangular que sirvió de testigo a las tumbas del linaje nazarí, se conservan piezas de mármol de gran formato dedicadas a guardar memoria de algunos sultanes y miembros de la familia gobernante y de otros altos funcionarios con tareas de responsabilidad política, fechadas o datadas en los siglos XIV y XV. Hace tiempo que las lápidas conservadas han sido editadas, estudiadas y completadas con ayuda del diván de Ibn al-Ŷayyāb (RUBIERA MATA, 1970) los epitafios registrados en la obra de Ibn al-Jatīb y las anotaciones del morisco Alonso del Castillo, que en el siglo XVI alcanzó a ver las de la Alhambra (ALMAGRO CÁRDENAS, 1879; LAFUENTE ALCÁNTARA, 1859; LÉVI-PROVENÇAL, 1931; DÍAZ GARCÍA, LIROLA, 1989; MARINETTO SÁNCHEZ, 1995; MARTÍNEZ NÚÑEZ, 2007). Las inscripciones de las lápidas de los sultanes Nazaríes no serán tratadas aquí en detalle, ya que la estructura seguida en su formulario necesariamente se ajusta a un patrón particular ${ }^{1}$.

\section{EPITAFIO DEL AÑO 835/1436}

La lápida nazarí objeto de mi interés se dio a conocer a través de la exposición España, encrucijada de civilizaciones, que promovió la Sociedad Estatal de Acción Cultural en el Exterior, visitando con ese motivo varias sedes museísticas en España y América. La ficha que acompaña el catálogo va firmada por Ángela Franco, reconocida especialista en arte románico (W.AA., 2007: p. 190). La pieza ingresó en el Museo Arqueológico Nacional [MAN] con la colección de objetos que en mayo de 1961 donó el abogado madrileño don Jesús Gabriel y Galán (1899-1966).

En mi opinión, para redactar la ficha del catálogo la autora se valió de la descripción que figura en un informe realizado por el investigador Asín Palacios, miembro de la llamada Escuela de Arabistas Españoles. Este informe se lee en la zona anepígrafa de la lápida sobre una placa de metal clavada sobre la piedra, al pie de la inscripción. La chapa es de formato rectangular (altura $18 \mathrm{~cm} \times 22 \mathrm{~cm}$ de anchura) y en cada uno de sus cuatro extremos tiene un clavo que a su alrededor desarrolla un pequeño cuadrado (3 cm de lado) que sobresale de la figura principal. Aparece clavada en la piedra sobre la parte inferior que carece de pulido o alisado ya que el mármol solo fue desbastado. Los clavos son de cabeza redonda, excepto en el ángulo inferior izquierdo donde fue sustituido por un tornillo que a su vez sujeta una chapita (1,5 cm de anchura); ésta lleva grabado el número 100 y supongo que es el que debió de darle su poseedor.

Dice esa anotación tallada con letras capitales en la placa fijada a la piedra:

Fragmento de una lápida sepulcral, árabe, de letra granadina, / del siglo XV de J. C. que después de frases de elogio dedicadas al / difunto dice: / Éste es el sepulcro del alfaquí y visir el Hach, digno de estima, / noble, puro Abubéquer, hijo del cáid y visir muy noble, excelso, glorio-/so, magnífico, Buabdala Mohámed Elyenexti oriundo de Jenexta (hoy / el Puig de Enesa, en el reyno de Valencia, distrito de Játiba). Murió / joven á 29 del mes de Chumada 2ªño 839 (corresponde al 19 del / mes de diciembre de 1435).

Una raya centrada, grabada en la siguiente línea [l.], separa esta nota de otra en letras capitales de tamaño mucho más pequeño. Ocupa dos renglones y su texto reza así:

Traducido por el profesor de árabe de la universidad central de Madrid el presbitero / Excmo. Sr. D. Miguel Asín y Palacios. Año de 1914.

\footnotetext{
1 Las estelas de la familia nazarí que se sometieron al informe de la Real Academia de la Historia han sido objeto de análisis (MARTÍNEZ NÚÑ̃E, 2007).
} 


\section{El duque de Santa Lucía}

Entre los miles de piezas antiguas que ahora posee el MAN procedentes de la donación del señor Gabriel y Galán destacan sobre todo los bronces y hierros que sin duda debió heredar el donante del Duque de Santa Lucía (VAQUERO, 1993: p. 470), pues consta que a principios del siglo XX algunos de los llamadores, tiradores y llaves de esta colección eran de la propiedad del noble español (ARTIÑANO, 1919: pp. 46, 48, 124-125, 140, núms. 189, 193, 427, 428, 465).

Pero para entender mejor la vinculación de esa colección con el donante hay que remontarse a su biografía. Hijo del conocido poeta salmantino José María Gabriel y Galán (1870-1905), como el resto de los descendientes del vate de Extremadura conservó los dos apellidos paternos por concesión del rey a su progenitor. Al morir su padre siendo un niño, el rey Alfonso XIII le pupila y le concede su tutela como hijo adoptivo a don Álvaro Pérez de Barradas y Fernández de Córdoba (18601939) y a su esposa doña María Salvadora Bermúdez de Castro y Díez (1864-1945), duquesa de Santa Lucía, prima del político, escritor, diplomático y entusiasta de las Artes, Salvador Bermúdez de Castro y O'Lawlor (1863-1945).

Además de obras de valor artístico y artesanal, el Duque de Santa Lucía coleccionó también otras piezas históricas. Se sabe que en 1912 adquirió una edícula romana con inscripción latina del siglo III d.C. -aparecida a finales del siglo XIX en Mérida- que formaba parte del lote de objetos cedidos por Gabriel y Galán al MAN (exp. 1962/34/1544) como ya han señalado otros autores (ALMAGRO BASCH, 1976; ABASCAL, GIMENO, 2000: p. 78, núm. 47).

Cuando muere en Roma sin descendencia, los materiales de la colección de Pérez de Barradas quedan en manos de su viuda. Al morir ésta en 1945, se menciona en una nota sobre la luctuosa noticia publicada en el diario «ABC» (20/09/1945) que en el palacio de San Bernardo -donde residía en Madrid- "se encontraba una curiosa colección de llaves y cerraduras desde la época romana hasta nuestros días" además de tapices, cuadros y porcelanas procedentes de Italia, de la famosa
Villa Farnesina, cerca de Roma, cuyos frescos de Rafael restauró el padre de la finada, duque de Santa Lucía.

Son las piezas que, casi treinta años después, cedió don Jesús al MAN y con ellas un fragmento de capitel, que se presume procedente del toledano palacio de Fuensalida, en cuyo frente repite el escudo de los López de Ayala y en el lateral las armas de los Castañeda (MAN no Inv. 1962/34/5).

Una pista sobre la posible procedencia del epitafio que aquí se estudia podría hallarse en la genealogía del duque de Santa Lucía don Álvaro Pérez de Barradas, Fernández de Córdoba, Bernuy y González de Aguilar, ya que perteneció a una de las más antiguas casas de la nobleza sevillana, como reza la necrológica que le dedicó el diario $A B C$ (edición de Sevilla, 21/01/1939). Nacido en el Puerto de Santa María, además de señor de Turullote fue XII marqués de Peñaflor, con grandeza de España, $X$ marqués de Cortes de Graena, II marqués de Bay y VIII de Quintana de las Torres. Los títulos de Bay y Quintana de las Torres responden a posesiones en Flandes y en Burgos, pero los otros se hallan en Andalucía, en las actuales provincias de Sevilla y Granada (MARTíN OJEDA, VALSECA, 2000). Ambos patrimonios andaluces se localizan en las poblaciones sevillanas de Écija y de Peñaflor; las otras haciendas se sitúan en la cara norte de Sierra Nevada, entre Guadix y la antigua capital nazarí, en el municipio de Cortes y Graena. Por ser conocida la afición coleccionista del Duque de Santa Lucía es posible que le ofrecieran en venta o le donaran la inscripción que nos ocupa, aparecida tal vez en alguna de estas poblaciones granadinas.

Reseñaré como anécdota que el marqués de Bay fue dueño de una casa en la calle San Vicente de Madrid donde, durante buena parte de la primera mitad del siglo XX, estuvo la vivienda de Asín Palacios que fue también sede de la incipiente Escuela de Arabistas Españoles. Al margen del prestigio de don Miguel en 1914, en el momento de solicitarle el informe pudo influir en el ánimo del Duque el hecho de tenerlo como inquilino (MARÍN et alii, 2009: p. 669, núm. 340). 


\section{LA LÁPIDA Y SU EPÍGRAFE}

La pieza que hoy guarda el MAN tiene el Número de Inventario 1962/34/15. Aparece reproducida en la página CER.es de la Red Digital de Colecciones de Museos de España del Ministerio de Educación, Cultura y Deportes (NI MANF 1962/34/15/P, imagen de Ángel Martínez Levas) (Fig. 1). Es una lápida de mármol de formato rectangular que ha perdido el cuerpo superior por rotura y también el lateral derecho, dañado con importantes mutilaciones, aunque éstas no afectan a la inscripción. La parte inferior de la lápida (unos $26 \mathrm{~cm}$ de altura) carece de talla y en ella solo fue pulida una superficie de unos $6 \mathrm{~cm}$. Las medidas actuales de la estela son: Altura 63 cm; Anchura 51,8 cm; Grosor 10,4 cm.

Si comparamos estas cifras con las que nos proporcionan otras laudas del siglo XV se puede sospechar que la lápida tuvo alrededor de un metro de altura. He podido determinar que en las inscripciones datadas en el siglo XV la interlínea se amolda en todas ellas a un

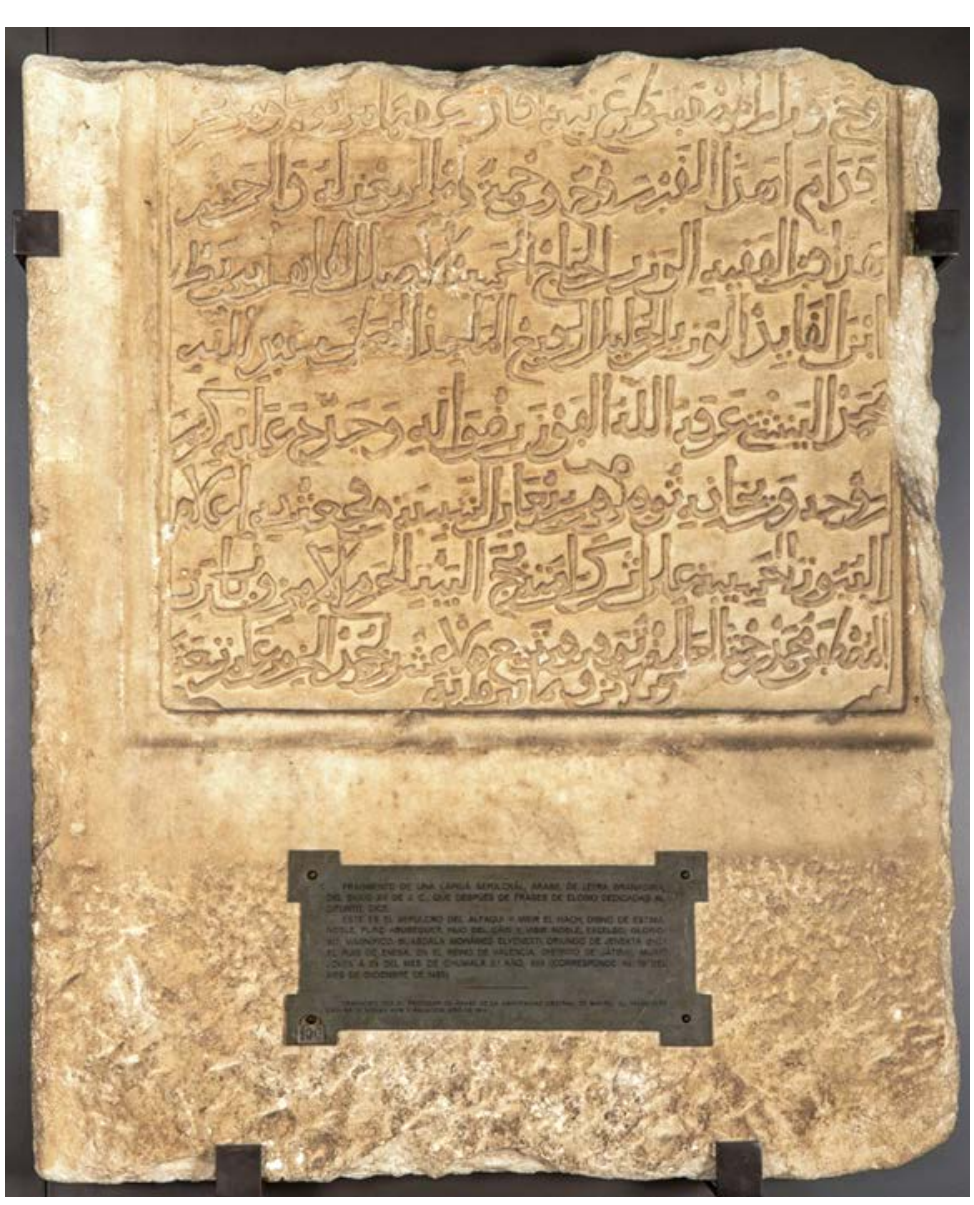

signo alif de unos $4,5 \mathrm{~cm}$ de altura, con una proporcionalidad de $1 / 15$. Esta medida difiere de la que se obtiene en los epígrafes del siglo XIV en los que la letra tiene menor elevación (unos 3,5 cm; proporcionalidad 1/10). Así pues, teniendo en cuenta estas características puede afirmarse que la inscripción que ostentó la lauda que estudiamos, además de las 8 líneas conservadas, pudo tener otras tres más; en conjunto exhibiría unos once o doce renglones.

El epígrafe aparece dentro de un recuadro que desde el filo exterior forma una cinta a modo de marco. Este recuadro debió envolver el campo central por los cuatro lados del rectángulo, pero solo se han conservado completos y pulidos el lateral izquierdo y la parte inferior descrita; ambos lados con una extensión de unos $6 \mathrm{~cm}$.

El campo epigráfico aparece hundido. Sus medidas son: Altura máxima conservada 37 $\mathrm{cm} \times$ una anchura de $40 \mathrm{~cm}$. Esta zona reservada a la escritura enlaza con el recuadro exterior en resalte mediante una sencilla moldura de nacela, un tipo de encuadramiento que gozó de mucha difusión en la arquitectura nazarí y se ve en otros epitafios granadinos. El artesano se vio en la necesidad de eliminar la nacela en la parte inferior del campo de escritura para poder incluir -centradas en ese espacio- unas palabras de la fecha y dotó de un semicírculo de adorno a los ángulos formados en los dos laterales.

Aunque los estudiosos suelen omitir el dato, resulta importante reseñar que

Figura 1. Lápida de al-Yanaštī (1436) en el MAN (Fotografía: Ángel Martínez Levas, Ministerio de Educación, Cultura y Deporte [http:// ceres.mcu.es]). 
en el grosor de las estelas del período nazarí pueden establecerse tres categorías: lápidas finas, con un espesor entre 3 y $4,5 \mathrm{~cm}$; medianas, entre 8 y 10,5 cm; y gruesas, entre 18 y 24 $\mathrm{cm}$. Los bordes de las gruesas y las medianas permitiría, si se consideraba necesario, grabar en el interior de cartelas (de unos 3 o 4,5 cm de altura) algunas pequeñas jaculatorias y fragmentos del Corán, como se observa en ciertas estelas. En los epitafios de miembros de la Casa de los príncipes granadinos esos cantos muestran el lema de la dinastía (wa lā gãlib illā Allāh) en el interior de cartelas de unos 5 × $12 \mathrm{~cm}$ (DÍAZ ESTEBAN, 1971; MARINETTO, 1995).

La inscripción de nuestra estela, que como se acaba de decir está fragmentada, conserva ocho líneas completas si bien en el centro de la última se incluyó en su interlínea otra de menor altura y extensión, por lo que en puridad el epitafio consta ahora de nueve. Las dos primeras líneas contienen los dos versos finales de una elegía por el difunto, aunque debieron ir precedidos de por lo menos otros dos versos que se perdieron al fracturarse la piedra. Los siete renglones restantes conservan el texto completo del epitafio. La escritura esculpida en relieve es cursiva y responde al tipo de caligrafía árabe denominada tult granadino, con la pluma cortada en un ángulo de $45^{\circ}$.

Respetando la escritura y el orden de las líneas conservadas, propongo la lectura siguiente:

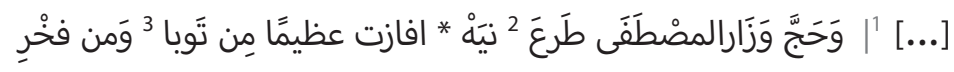

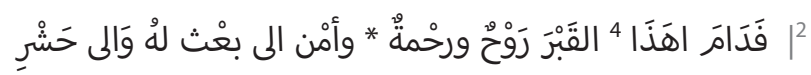

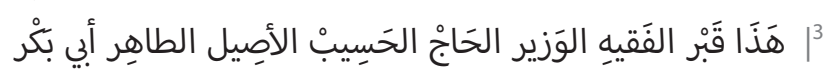

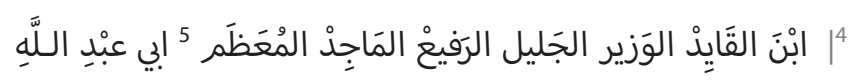

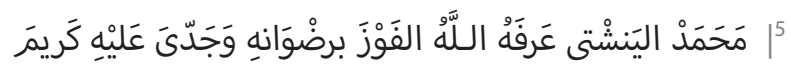

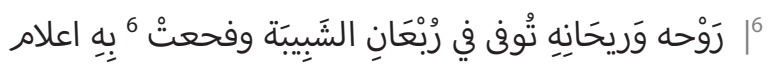

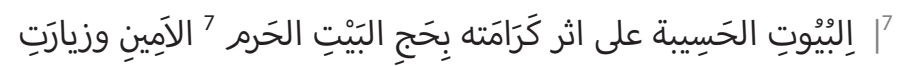

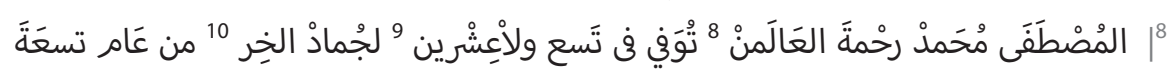

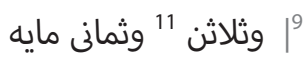

[...] 1| Peregrinó y visitó al elegido, lleno de un propósito * que hizo conseguir una enormidad de contrición y de mérito $2 \mid$ Perduren en esta tumba reposo, misericordia * y seguridad de que se le envíe (al cielo) y a la resurrección (metro țawill, rima -ri) 3| Ésta es la tumba del faqīh, el wazir, el hā̂ŷy noble, preclaro y puro, Abū Bakr 4 | hijo del qă'id, el wazîr querido, excelso, famoso y honrado, Abū 'Abd Allāh 5| Muhammad al-Yanaštī ¡Dios le otorgue la salvación con Su complacencia y le conceda Su generoso 6| reposo y Su aroma ${ }^{12}$ ! Murió en la primavera de la juventud. Sufrieron su pérdida las personalidades $7 \mid$ de las nobles casas después de habérsele concedido peregrinar a la garante Casa Sagrada y visitar 8| (la tumba de) Mahoma, el elegido, clemencia de los mundos. Murió en el vigésimo noveno (día) de la última ŷumada del año nueve 9| y ochocientos treinta [equivale a 19 de enero de 1436].

\begin{tabular}{|c|c|}
\hline 2 Sic por ترع & 7 Sic por الحَررام \\
\hline Sic por S تَوب Sic & 8 Sic por رحْمةَ العَالَمينْ \\
\hline 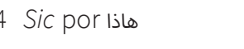 & 9 Sic por في التاسع والعشرين \\
\hline Corregido sobre ابي & لجُمَادى الآخِرة 10 Sic por \\
\hline Sic por وفجعتْ & 11Sic por وثلاثين \\
\hline
\end{tabular}

12 He interpretado ŷaddà (conceder), pero podría ser $\hat{y} a d d a d a$ (renovar), como explico en el comentario epigráfico. Como me indica generosamente uno de los evaluadores, el texto alude a Q LXVI, 89. Sigo la traducción del texto coránico efectuada por Juan Vernet. 


\section{COMENTARIO EPIGRÁFICO}

El texto se grabó en un único nivel de escritura que coincide con el renglón o línea base. La sola licencia tomada fue trazar, casi al final de la I. 7, la primera letra de ziyārāt sobre la precedente, recurso seguido en otras estelas granadinas de los siglos XIV y XV. En la inscripción el artesano cometió un considerable número de faltas, algunas debidas a la interferencia del árabe hablado por lo que las podemos considerar meros reflejos de la lengua dialectal. Unas y otros delatan que existió un texto del epitafio escrito sobre papel, de cuyo original se sirvieron para trasladar su contenido fúnebre a la lápida.

Prueba de ello es que sobre la línea y encima de tuwuffiya (l. 6) aparece grabada (¿tal vez por error?) la letra s del inicio de sahih, que es la abreviatura de "vale" usada por los escribanos árabes para indicar que lo corregido es correcto.

En algún caso se emplearon dos tipos de grafía para un solo fonema, lo que podría significar que el artesano respetó los defectos y erratas que tenía el texto escrito en papel; o que olvidó algún carácter distintivo; o bien que se trata de una variedad de letra en el alfabeto usado en el reino de Granada, como aparece en la ță' de al-musțtafà (l. 1 y I. 8), trazada de dos maneras (Fig. 2).

El grabador marcó en la piedra la puntuación occidental, es decir señaló la letra fā' con un punto bajo el renglón y la qāf con un diacrítico encima; entre los grafemas auxiliares eligió šadda, que se usa para la geminación (I. 1; I. 4), y silencio (sukūn), aunque éste falte en algunas palabras y en otras descubra formas pausales, muy frecuentes en inscripciones nazaríes: al-hāŷy (I. 3), al-qāyid, al-rafï', al-māŷid (l. 4), al-'álamin (l. 8); así

Figura 2. Alfabeto de 1436 (Dibujo del autor) mismo usó los tres signos vocálicos, aunque no de manera sistemática; en la inscripción de los versos empleó también los signos de caso e indeterminación, aunque no siempre de forma acertada (v.gr. tawban por tawbin casi al final de l. 1).

Se aprecian varias erratas de labra cometidas por el lapicida: un solo punto diacrítico resuelve la lectura de $f y$ y en fuŷi'at (l. 6); el de $n$ en 'išrīn se aprovechó para puntuar ŷumād (l. 8); faltan los de la vocal larga de al-wazir (I. 3) y en el término al-așil están bajo la letra șād (l. 3). Se advierte en la l. 2 un texto dialectalizante (fa-dāmā had̄ā) en vez de la forma gramatical correcta.

Otros errores de talla son: un desfigurado alif maqșūra en ŷaddà (I. 5; a menos que se trate de la última d de ŷaddada) que quedó con el cuerpo inferior un poco deforme (como si fuera $h \bar{a}$ ) y al que se le colocó la vocal a del signo auxiliar de geminación; además, en a lām (l. 6) no se marcó la obligada separación entre el dígrafo lām-alify la letra final; abì (l. 4) se ve tallado medio oculto por la forma restaurada al-mu'azzam grabada encima (Fig. 2).
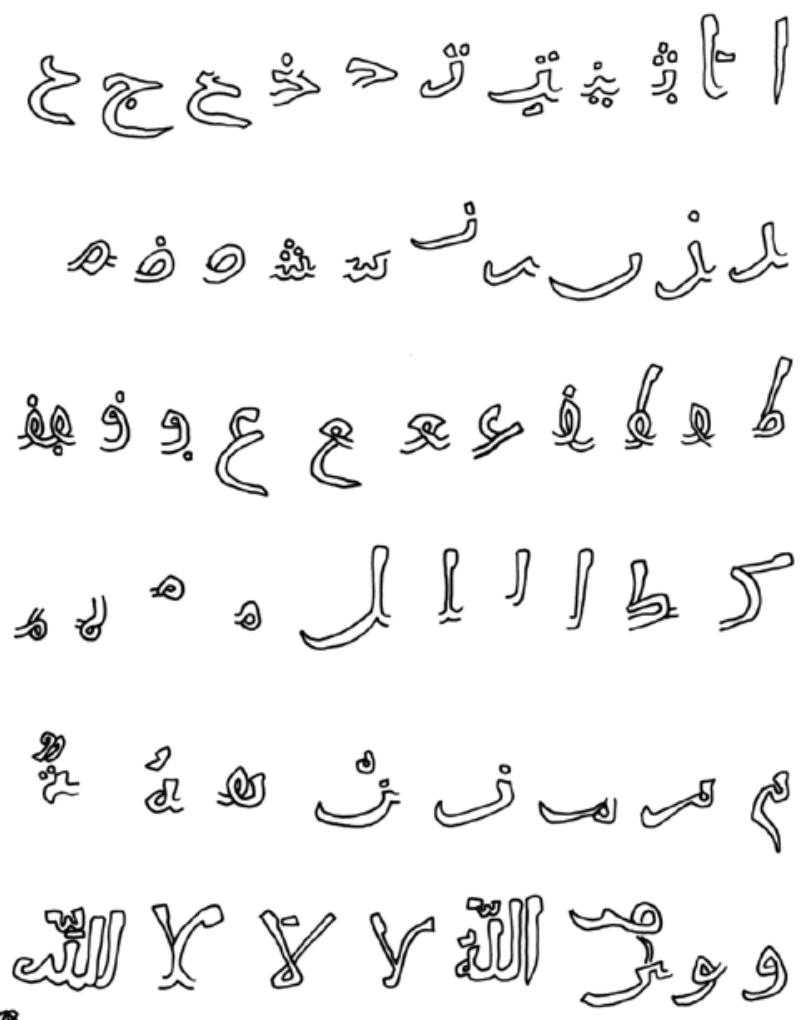
He detectado escrituras que delatan problemas para representar la cantidad vocálica: al-haram (I. 7), al-'álamin (I. 8), tasi' (I. 8), talātin (I. 9); en țari'a (I. 1) hay además un ejemplo de confusión de dentales (/ț/-/t/), conocido rasgo dialectal andalusí. El epígrafe confirma la doble forma que el dialecto da al nombre propio Muhammad -hecho señalado hace tiempo por Granja (1968: p. 235)- pues el artesano grabó en el epígrafe Muhamad (l. 8) para referirse a Mahoma, pero Mahamad (I. 5) en el nombre del padre del difunto. Como ocurre en la vocalización tuwaffiya del verbo no-agentivo (I. 8), hay también articulación dialectal en las junturas ibna-l-qāyid (l. 4), fi-t-tasi'wa-l-'išrin (l. 8) y li-ŷumāda-l-ajir (l. 8), nombre del mes lunar que en dialecto es tratado como masculino.

En cuanto a la fecha del óbito, se indica solo el día del mes, usando (no sin problemas) la serie ordinal, como determina la gramática árabe. Se da el nombre del mes y se acaba con la data anual, usando la voz 'àm que en esta época era ya mención obligada. En cuanto a la correspondencia con el año cristiano, erró Asín Palacios en sus cálculos, pues no estamos en diciembre del año 1435, sino en enero del bisiesto 1436 que teóricamente comenzó el 11 de ŷumādà al-ajīra del 839 de la hégira.

\section{Al-Yanaštī}

Por el texto del epitafio venimos en conocimiento del apellido por el que fue conocido el difunto y que se debía de remontar al patronímico de los antepasados. Don Miguel Asín tampoco estuvo acertado aquí al identificar Yanašta con el lugar de El Puig, punto en el que fueron derrotados en 1237 los habitantes de Valencia por las tropas de Jaime I. Esta elevación era conocida entre los andalusíes por Aniša y la documentación coetánea árabe así lo recoge; también la latina, que respetó el nombre Enesa de aquella pequeña colina, el puig en catalán (LABARTA et alii, 2011: [384], [420]).

El patronímico al-Yanaštī podría aludir a una localidad de al-Andalus que citan algunos geógrafos medievales cuando describen su territorio; por ejemplo, el oriental Yāqūt ('ABD AL-KART̄M, 1974) situó la ciudad de Chinchilla entre las de Xàtiva y Yanašta. El también oriental al-Himyarī coloca su castillo (hișn Yanašta) a dos días de viaje de Chinchilla (ABBĀS, 1975). Los diccionarios biográficos recogen en esta localidad, que alguna vez citan dando nombre al castillo (hișn Yanāšta), durante los siglos XI y XII varios sabios -algunos de tendencia sufíademás de los antepasados de Abū-l-'Abbās al-Yanaštī, alzado en Ceuta en 1233, de quien hacen memoria los historiadores de época almohade (ABBĀS, 1975).

Por lo tanto, se ha podido concluir que la Yanašta citada en las fuentes históricas árabes es la población conquense que ocupó Alfonso VIII para la Corona de Castilla en 1186 y se halla hoy junto a la carretera de Madrid a Valencia. La actual forma Iniesta es fruto de la adaptación castellana, contaminada con el nombre latino de la retama; tal vez en el reino de Granada llegara a decirse Yaništa con disimilación vocálica o respetando una antigua ortografía que reflejaba la vocal /e/ (BARCELÓ, 2001: pp. 494-495).

El hecho bélico del siglo XII hizo que la población allí residente emigrara, buscando refugio en tierras levantinas entonces bajo gobierno almohade. Cuando su habitantes cedieron ante las tropas de la Corona de Aragón a principios del siglo XIII, unos y otros emprendieron la fuga hacia sitios más seguros en el sur peninsular. Parece confirmarlo así Ibn al-Jațīb, que dedica una biografía a su paisano Abū Bakr 'Abd al-Rahmān bn 'Abd alMalik al-Yanaštī, nacido en Priego de Córdoba, criado en Loja y fallecido en Granada en 1358 como consecuencia de la peste ('INĀNN, 1975, II: 527-529).

Considero probable que el finado a quien se dedicó nuestro epitafio descendiera de ese personaje. Además de que el patronímico coincide, llevó la misma kunya; quizá el nombre propio 'Abd al-Rahmān del letrado granadino (W.AA., 2012: VII, 268-269, nº 1861) fuera también compartido por el difunto. A tenor de las fechas en que vivieron uno y otro no se puede descartar que, si se tratase 
de parientes, el difunto de la lápida del MAN podría haber sido un nieto del granadino citado por el famoso polígrafo de Loja. Siendo su nieto, la coincidencia onomástica se justifica por sí sola y en cuanto a Muhammad, padre de nuestro finado, pudo ser hijo del 'Abd al-Raḥmān de Iniesta pues entre ambos solo mediaría una generación.

\section{ESTRUCTURA DEL EPITAFIO}

A la muerte de Sa'd Ibn Mardanī̌s (1176), las tierras que controlaba en el Levante se sometieron al gobierno de los almohades que así llegaron a unificar al-Andalus. A partir de entonces los epitafios fechados en el último cuarto del siglo XII y buena parte del XIII, conservados en variados soportes tanto desde el punto de vista del material usado (mármol, arenisca, granito, cerámica) como de formato (rectangular liso, con enmarque, con arco inscrito y enmarque, tumular, etc), comparten elementos estructurales en sus textos y a partir de la independencia y unificación del sureste peninsular bajo el mando de los nazaríes el contenido de esos elementos fue aumentando poco a poco e incluso los que se hicieron en áreas afines de tierras mudéjares mantienen entre sí cierto parecido, aunque su número es escaso.

La pieza estudiada aquí presenta en su formulario una secuencia que puede ser puesta en relación con la de piezas fechadas desde el siglo XIII al XV. En los epitafios conocidos se distinguen las siguientes fórmulas: a) introducción; b) presentación del onomástico; c) jaculatorias piadosas seguidas del curriculum del difunto; d) fecha del óbito y oraciones de conclusión.

\section{a) Fórmula de introducción}

Aunque la lápida de al-Yanaštī de 1436 no conserva el preámbulo, se puede restituir una primera línea que sin ninguna duda llevaba basmala y tașliya.
En los tres siglos analizados y en el 95\% de las estelas, la basmala completa se graba en la línea que inicia el epitafio; no obstante, hasta 1270 lo encabeza la fórmula conocida por hamdala, solo precedida -a veces- de ta'awwud, esto es "Me libre Dios del maldito demonio", jaculatoria que se repite diariamente durante la oración ritual y que el Corán exhorta a decir cuando alguien lo recite $(\mathrm{Q} X \mathrm{VI}$, 98); por esta razón ta'awwud da paso a una cita del texto sagrado (BARCELÓ, 1990: p. 45; 1998: p. 88). Si bien la mención coránica no exige usar esta formulación, en al-Andalus es frecuente, por lo menos desde el siglo XII, ver la triple secuencia inaugural ta'awwud, basmala, tașliya en paredes de mezquitas y de edificios de carácter político, así como en objetos de representación del poder.

A estas tres fórmulas, en el orden ta'awwud, basmala, tașliya, sigue en el epitafio la aleya 33 de Q XXXI (Mallorca sin fecha [s.f] antes de 1229; Almería 623/1226), que contiene la conocida y repetida Q XXXV, 5 (BARCELÓ, 1990: p. 45), usada también sin ta'awwud en un epitafio mudéjar (660/1261-1262) de Toledo ${ }^{13}$ y en Almería (718/1318).

Cuando la estela tiene solo texto sagrado, ta'awwud puede ir sin basmala ni tasliya (Baza s.f, Q III, 185; Córdoba 587/1191, también con Q IX, 128-129 en el marco de la estela); o bien -sin tasliya- seguido de basmala o no, como en un túmulo hallado en Torrijos (s.f) con selección coránica alejada del gusto andalusí.

Además, en el siglo XIII se elige Q III, 185 (Jaén 661/1263; Vinaròs 639/1241), aleya que se ve (sin ta'awwud) en el campo central de un trozo de estela hallado en la ermita de San Tomé de Aguiã (sin fecha [s.f]; Arcos de Valdevez, Braga, Portugal) y en una lápida extraviada (Granada 833/1430). La conservada en el Puerto de Santa María (s.f) lleva en el canto de la losa dos fórmulas de la tríada y entre ambas el versículo que exhorta a decir tașliya (Q XXXIII, 56).

\footnotetext{
13. Esta pieza toledana se ha considerado del siglo XI por llevar esta aleya (BARCELÓ, 1990: p. 52); el error quizá se deba a no haber estudiado en profundidad el protocolo de los epitafios de los siglos XIII al XV.
} 
Esta fórmula puede faltar en zonas mudéjares aunque desde la etapa almorávide tașliya estuvo presente de manera casi constante (BARCELÓ, 1990: p. 51). En relación con el epitafio del período aquí tratado, en el siglo XIII se halla formulada sencilla (52\%) (șallà Allāh 'alà Muhammad, seguida en menor proporción por wa-('alà) āli-hi). A mediados de la centuria -solo en pocos casos (10\%)se amplía su enunciado a wa-șallà Allāh 'alà sayyid-nā Muhammad wa-'alà āli-hi wasallama taslìman, que será la jaculatoria mejor documentada en los siglos XIV y XV (casi el $30 \%$ ) y que sería la usada en la estela de 1436 de al-Yanaštī; no obstante, mediado ya el siglo XIV solo la epigrafía oficial la amplía con wa-mawlā-nā.

\section{b) Fórmula de presentación del onomástico}

Como señala Barceló (1990: pp. 45-46), la expresión "ésta es la tumba de..." (hādāa qabr), seguida del nombre del difunto, aparece invariablemente tras la fórmula de inauguración y de la cita coránica, si la tuviere. Sólo una vez se utiliza el sinónimo hāda a darị en una estela granadina sin fecha (LÉVI-PROVENÇAL, 1931: no 177).

En el siglo XIII hādā qabr puede faltar y en su lugar está "murió" (tuwuffiya). Así se halla al menos en piedras tumulares (Mallorca s.f; Málaga 1221) y lápidas rectangulares (Almería 1226; Jaén 1263; Moura (Beja) 769/1368). Es el orden también de dos estelas cerámicas (Málaga 768/1366; Huelva 811/1440), si bien en la pieza discoidal del siglo XV el preámbulo es diferente (hamdala) e igual al que figura en una lápida hallada en Zalia (Alcaucín, Málaga 746/1345).

Se conocen los versos que figuraban en la cara opuesta de los epitafios de los sultanes nazaríes, al menos desde el siglo XIII, pero sus súbditos no parece que siguieran su ejemplo pues documentalmente no aparecen en los epitafios hasta el siglo XV, cuando se empiezan a usar unos cuantos versos elegíacos antes de la fórmula de presentación "ésta es la tumba de...." La inclusión de poesías en los epitafios islámicos medievales ha sido objeto de interés, sobre todo al estudiar la producción literaria conservada en los divanes de autores conocidos (RUBIERA, 1970); y se ha podido hacer también un repertorio de textos, desde un pareado hasta cuatro o cinco versos grabados en estelas y otro tipo de soportes epigráficos (BARCELÓ, 2000).

En el reino de Granada el número de versos fluctúa entre dos (Santafé 806/1404), cinco en las estelas de dos hermanos (845/1441) que se han conservado en Córdoba (LÉVIPROVENÇAL, 1931: no 183, 184) y siete que se contabilizan en el fragmento lateral de una lápida sin fecha (MAPGr No Inv. 1859). La pieza de al-Yanaštī, aunque solo conserva dos de los cinco versos que tal vez se grabaran, viene a confirmar la datación en el siglo XV de aquella moda.

Desde época almorávide se introduce la costumbre de citar al difunto por su kunya, precedida del oficio o título-uno o varios-que hubiera alcanzado en vida. Los más citados son: šayj, qā'id, wazīr, faqīh y hā̄ŷy; son menos frecuentes jațib, țālib, amin; y solo se usa imām como tratamiento de los sultanes y los miembros de la familia nazarí.

Poco a poco esa introducción se acompaña del término 'joven' (šābb[a]), cuando ésta era la edad del finado, y se agranda con fórmulas elogiosas respecto a las acciones que llevó a cabo el fallecido durante su estancia en esta tierra, de manera que el preámbulo onomástico se alarga dos o tres líneas con una prosa rimada que hace difícil una simplificación común a todos los epitafios.

En los más de ochenta epitafios analizados he podido contabilizar, fuera de la prosa rimada, más de una cincuentena de variantes; además de los más frecuentes que ahora citaré, se documentan 18 participios, 7 adjetivos calificativos y 18 formas elativas. Un adjetivo casi omnipresente es al-yalïl o al-aŷall, incluso con mujeres. Le siguen en presencia al-muŷāhid y al-țāhir - al-athar; otros de menor frecuencia son: al-mu'azzam, al-rafí', al-afdal, al-așil, al-asmà, al-hasīb, seguidos de al-arfa'a, al-akbar, al-kabìr, al-māŷid, al-a'azz. 
Este esquema se halla también en estelas cerámicas y en tierras mudéjares, en las que se hace especial mención a unos adjetivos que se repiten de manera invariable a lo largo de los siglos. A partir del siglo XIV se convierten en cita obligada los adjetivos "el santo finado" (al-muqaddas al-marhūm) antes de dar su nombre; y se repiten delante del nombre de los ascendientes cuando éstos ya habían muerto.

La relación con el padre se indica con el término "hijo de...", al que sigue la kunya y nombre propio del progenitor precedida también de su oficio, títulos y adjetivos. La cadena ascendente puede remontarse dos generaciones, raras veces tres y el último familiar lleva el patronímio o gentilicio del linaje. En el caso de los sultanes y gobernantes nazaríes esta relación de parientes es mucho más prolija; incluye el título honorífico del difunto y de cada uno de los antepasados, usando adjetivos específicos distintos a los que se ven en otros epitafios, destacando al-humām, al-as'ad, al-ašhar o al-šahìr y al-a'là.

\section{c) Jaculatoria piadosa y datos del curriculum}

El epitafio andalusí incluye tras el onomástico la jaculatoria "Dios se apiade de él (o de ella)" (rahima-hu Allāh o bien rahmat Allāh 'alay-hi), que es la más frecuente; en los siglos XIV y XV se acompaña a veces con un "y le perdone" (wa- 'afā 'an-hu) o se reemplaza con "santifique Dios su espíritu y enfríe su tumba" (qaddasa Allāh rüha-hu wa-barrada ḍrịha-hu) u otras similares del tipo "ponga el paraíso como morada suya” (wa-ŷa'ala al-ŷanna ma'wā-hu), cuyos usos en épocas anteriores ya no ofrecen dudas (BARCELÓ, 1990: p. 46-47). A partir del siglo XIV se suele usar, como se ve en un túmulo de Niebla (OCAÑA, 1964: n 119), la expresión "Dios haga que saque provecho de..." (nafa'a-hu Allāh bi-) que puede alargarse en prosa rimada.
La jaculatoria elegida en el epígrafe de al-Yanaštī es "iDios le otorgue la salvación con Su complacencia y le conceda Su generoso reposo y Su aroma!" ("arafa-hu Allāh al-fawz bi-ridwāni-hi wa-ŷaddà 'alay-hi karìm rawhihi wa-rayhāni-hi) que, además de su alusión coránica y a pesar de su típica redacción en prosa rimada de la etapa nazarí, parece tener cierto paralelismo con la oración "Dios le cubra de Su piedad y Su misericordia" (taġammada-hu Allāh bi-l-rawh wa-l-rayhān), presente en la estela del nieto de un mawlà de los nazaríes fallecido a mediados del siglo XV (LÉVI-PROVENÇAL, 1931: no 184, Im. 43b). Esta fórmula y otras de parecido tenor piadoso, presentes en epitafios granadinos, pueden rastrearse en los tres primeros versos del poema que figura sobre la tumba de Yūsuf III (LÉVIPROVENÇAL, 1931: p. 172 no 182; LAFUENTE ALCÁNTARA, 1859: p. 159; PUERTA VÍLCHEZ, 2010: p. 280), cuya muerte en 820/1427 nos da una pista sobre la fecha en que estas expresiones se difunden.

Después de la oración, el epitafio de al-Yanaštī incluye breves datos sobre su vida. El uso de esta nueva formulación aparece ya a finales del siglo XIII en las estelas de dos arraeces Ašqīlūla, señores de Guadix y Comares. A partir de esta época, se da noticia en prosa rimada - de extensión más o menos largasobre las vicisitudes de la vida del finado, que pudo "gastar lo que tenía... por amor a Dios" (anfaqa-hu mā... fĩ sabil Allāh); o bien puede incluirse ${ }^{14}$ una señalización del lugar de su sepultura (dufina bi-hadihi l-ŷabbāna) e incluso las causas de su muerte, por ejemplo de una caída del caballo (GARCíA GÓMEZ, 1942).

\section{d) Fecha del óbito y conclusión}

Al finalizar las noticias sobre el difunto es opcional incluir el verbo "nació" (wulida) seguido de la fecha. Si este dato no se consigna a veces, también puede faltar "murió" (tuwuffiya) con nueva repetición de jacula-

\footnotetext{
14. Aunque la pieza se descubrió en Alcalá la Real, el epitafio dice que el cementerio estaba en Granada; podría tratarse del que las fuentes llaman ŷabbānat bāb al-fajjārīn (DÍAZ, LIROLA, 1989: p. 116).
} 
torias. Viene después la data en la que se produjo la defunción, usando palabras para indicar la fecha. Ésta aparece formulada de modo invariable desde el siglo XII: feria de la semana, a menudo introducida con la preposición fï; día, expresado con numerales ordinales; la mención del mes, incorporada con la preposición li- o min; y el año que, salvo raras excepciones, es siempre la palabra 'ām y aparece a menudo precedida de la preposición min o fĩ. El momento o la hora de la oración ritual se incluye solo en los epitafios de los sultanes nazaríes.

Si hay espacio suficiente en la lápida, después de la fecha se incluye al final una piadosa oración, a menudo una tașliya que se amplía con otros adjetivos elogiosos y expresiones relacionadas con la misión de Mahoma.

\section{BIBLIOGRAFÍA}

ABASCAL, J. M.; GIMENO, H. (2000): Epigrafía Hispánica. Catálogo del Gabinete de Antigüedades. Madrid, Real Academia de la Historia (con la colaboración de Isabel Velázquez. Pizarras visigodas).

'ABBĀS, I. (1975): AL-ḤIMYARĪ. Kitāb al-rawd al-mi'țār fī jabar al-aqțār. Beirut, Librería Bayrūt.

'ABD AL-KARĪM, G. (1974): La España musulmana en la obra de Yāqūt (s. XII-XIII). Granada, Cuadernos de Historia del Islam 6.

ACIÉN ALMANSA, M. (1978): "Estelas cerámicas epigrafiadas en la Alcazaba de Málaga”, Baetica. Estudios de Arte, Geografía e Historia. 1, pp. 273-278.

ACIÉN ALMANSA, M. (1996): "Cerámica y propaganda en época almohade”. Arqueologia Medieval. 4, pp. 183-191.

ACIÉN ALMANSA, M.; MARTÍNEZ NÚÑEZ, M. a A. (1982): Catálogo de las inscripciones árabes del Museo de Málaga. Madrid, Ministerio de Cultura.

ACIÉN ALMANSA, M.; MARTÍNEZ NÚÑEZ, M. ${ }^{a}$ A. (2003): "Datos arqueológicos sobre la presencia meriní en Málaga”, Mainake. 25, pp. 403-416.

ALMAGRO BASCH, M. (1976): "Antigüedades de Mérida en el Museo Arqueológico Nacional. Augusta Emerita", Actas del Simposio Internacional conmemorativo del Bimilenario de Mérida (Mérida, 1975). Madrid, Dirección General del Patrimonio Artístico y Cultural y Patronato de la Ciudad de Mérida, pp. 127-139.

ALMAGRO CÁRDENAS, A. (1879): Estudios sobre las inscripciones árabes de Granada. Granada, Ventura Sabatel.
ALMERÍA (2007): Luminaria: Dos milenios de cristianismo en Almería. Catedral de Almería, de mayo a septiembre de 2007. Almería, Obispado de Almería.

ARTIÑANO Y GALDÁCANO, P. M. de (1919): Exposición de hierros antiguos españoles. Catálogo. Madrid, Sociedad Española de Amigos del Arte.

BARCELÓ, C. (1990): "Estructura textual de los epitafios andalusíes (siglos IX-XIII)", Homenaje a Manuel Ocaña Jiménez. Córdoba, Diputación de Córdoba, pp. 41-54.

BARCELÓ, C. (1998): La escritura árabe en el País Valenciano. Inscripciones monumentales. Valencia, Universidad de Valencia.

BARCELÓ, C. (2002): Adaptación arábiga de los topónimos antiguos, Congrès Internacional de Toponímia i Onomàstica Catalanes (València 18-21 d'abril de 2001). Valencia, Universitat de València - Denes, pp. 489-510.

BARCELÓ, C. (2000): "Poesía y epigrafía. Epitafios islámicos con elegía, desde Suakin a Almería", Anaquel de Estudios Árabes. 11, pp. 123-144.

BARCELÓ, C. (2006): "Túmulo islámico del Museo Histórico Municipal de Écija”, Astigi Vetus. Revista del Museo Histórico Municipal de Écija. 2, pp. 131-138.

BARROCA, M. J. (2000): Epigrafia medieval portuquesa (862-1422). Lisboa, Fundação Calouste Gulbenkian. 3 vols.

BORREGO, M. A. (2014): Epigrafía andalusí. Inscripciones árabes de Jerez de la Frontera. Cádiz, Ayuntamiento de Jerez.

BOURRILLY, J.; LAOUST. E. (1927): Stèles funéraires marocaines. París, Institut des Hautes-Études Marocaines.

CABRÉ, D.; CUGAT, F. (1986-1987): "Estela i cementiri sarraïns de Riba-Roja (Ribera d'Ebre)”, Butlletí Arqueológic. Reial Societat Arqueológica Tarraconense (Època V). 8-9, pp. 235-240.

CASA, C. de la; DOMENECH, M. (1984): "Inscripción árabe en un cuenco procedente de Ágreda (Soria)", Celtiberia. 34, pp. 319-322.

CASA, C. de la; JUSUE, C.; MENCHON, J. (1989): "Estelas medievales cristianas de la Península Ibérica”, III Congreso de Arqueología Medieval Española. Oviedo. Actas. Ponencias. Oviedo, Universidad de Oviedo, I, pp. 237-254.

CASKEL, W. (1936): Arabic inscriptions in the Collection of the Hispanic Society of America (traducido del alemán por Beatrice Gilman Proske). New York, Hispanic Society of America.

COMBE, E.; SAUVAGET, J.; WIET, G. (1934-1975): Répertoire chronologique d'épigraphie arabe. Le Caire, Institut français d'archéologie orientale du Caire.

DÍAZ ESTEBAN, F. (1971): "Dos lápidas musulmanas en Torrijos (Toledo)", Boletín de la Asociación Española de Orientalistas. 7, pp. 159-170. 
DÍAZ GARCÍA, A.; LIROLA DELGADO, J. (1989): "Nuevas aportaciones al estudio de los cementerios islámicos en la Granada nazarí", Revista del Centro de Estudios Históricos de Granada y su reino (Segunda época). 3, pp. 103-126.

EL AOUDI ADOUNI, R. (1997): Stèles funéraires tunisoises de l'époque hafside (628-975 / 1230-1574). Tunis, Institut National du Patrimoine.

FERNÁNDEZ GUIRADO, I. (1993): "Informe arqueológico del sondeo realizado en calle Agua no 16 (Málaga)", Anuario Arqueológico de Andalucía / 1991. Actividades de Urgencia. Cádiz, Dirección General de Bienes Culturales, pp. 319-325.

FERRANDIS TORRES, J. (1935): "Estelas cerámicas", AlAndalus. 3.1, pp. 179-180.

GARCÍA GÓMEZ, E. (1942): "Sobre los epitafios de dos caballeros Abencerrajes y otra lápida granadina desconocida", Al-Andalus. 7.2, pp. 283-297.

GARCÍA LARIOS, M.a J. (2006): "Una tumba nazarí de estelas anepigráficas”, Arqueología y Territorio Medievales. 13.2, pp. 145-155.

GONZÁLEZ MARTÍ, M. (1952): Cerámica del Levante Español. Siglos medievales. Madrid, Labor. 3 vols.

GRANJA, F. de la (1968): "A propósito del nombre Muhammad y sus variantes en Occidente", Al-Andalus. 33.1, pp. 231-240.

GUILLÉN ROBLES, F. (1880): Málaga musulmana. Málaga, Ayuntamiento [2a. ed. 1957].

'INĀN, M. A. A. (1973-1977): IBN AL-JATīỉ. Al-Ihāta fí ajbār Garnāta. El Cairo, Compañía Egipcia de Ėdiciones y Publicaciones (2a. ed. 4 vol.).

JIMÉNEZ GADEA, J. (2002): "Acerca de cuatro inscripciones árabes abulenses", Cuadernos Abulenses. 31 , pp. 25-71.

JIMÉNEZ GADEA, J. (2009): "Estelas funerarias islámicas de Ávila: clasificación e inscripciones”, Espacio, Tiempo y Forma. Serie I, Nueva época. Prehistoria y Arqueología. 2, pp. 221-267.

LABARTA, A. (1990): "Las lápidas árabes de la provincia de Jaén", Homenaje a Manuel Ocaña Jiménez. Córdoba, Diputación de Córdoba, pp. 123-137.

LABARTA, A. (2015): "Epigrafía árabe sobre piedra en el Garb al-Andalus", Epigrafía árabe y Arqueología medieval. Granada, Alhulia, pp. 205-238.

LABARTA, A.; BARCELÓ, C.; VEGLISON, J. (2011): València àrab en prosa i vers. Valencia, Universidad de Valencia.

LAFUENTE ALCÁNTARA, E. (1860): Inscripciones árabes de Granada. Madrid, Imprenta Nacional (pp. 156-168 y 207-240).

LÉVI-PROVENÇAL, E. (1931): Inscriptions arabes d'Espagne. Leiden - Paris, Brill - Maissonneuve.
LIROLA DELGADO, J. (2015): "La información histórica aportada por la epigrafía: el caso de Almería", Epigrafía árabe y Arqueología medieval. Granada, Alhulia, pp. 239-254.

LISBOA (1998): Portugal Islâmico. Os últimos sinais do Mediterrâneo. Lisboa, Museu Nacional de Arqueologia.

MADRID (2007): España, encrucijada de civilizaciones Centro Cultural Palacio de la Moneda. [Madrid], Sociedad Estatal de Acción Cultural en el Exterior - [Barcelona] Lunwerg.

MANCILLA CABELLO, M. I.; ROMÁN PUNZÓN, J.M. (2010): "Intervención arqueológica mediante seguimiento en Cuesta del Realejo, n 26 (Barrio del Realejo, Granada)", Anuario Arqueólogico de Andalucía 2004.2. Sevilla, Dirección General de Bienes Culturales, pp. 469-476.

MARÍN, M.; PUENTE, C. de la; RODRÍGUEZ MEDIANO, F.; PÉREZ ALCALDE, J. (2009): Los epistolarios de Julián Ribera Tarragó y Miguel Asín Palacios. Madrid, Consejo Superior de Investigaciones Científicas.

MARINETTO SÁNCHEZ, P. (1995): "Epitafios. Losas sepulcrales", Arte islámico en Granada. Propuesta para un Museo de la Alhambra. Granada, Comares, pp. 409-414.

MARTÍN OJEDA, M.; VALSECA CASTILLO, A. (2000): ÉCija y el marquesado de Peñaflor, de Cortes de Graena y de Quintana de las Torres. Churriana de la Vega, Ayuntamiento de Écija.

MARTÍNEZ CAVIRÓ, B. (1982): La loza dorada. Madrid, Editora Nacional.

MARTÍNEZ CAVIRÓ, B. (1991): Cerámica Hispanomusulmana. Madrid, El Viso.

MARTÍNEZ CAVIRÓ, B. (2010): La loza dorada en el Instituto de Valencia de Don Juan: Oro y lapislázuli. Madrid, Orts Molins.

MARTÍNEZ ENAMORADO, V. (1997): "Una lápida funeraria de época nazarí", Al-Andalus-Magreb. 5, pp. 111-117.

MARTÍNEZ ENAMORADO, V. (2005): "Más sobre epigrafía nazarí y meriní a partir de la lápida de Cañete de las Torres conservada en el Museo Arqueológico de Córdoba", Anales de Arqueología Cordobesa. 16, pp. 239-258.

MARTÍNEZ NÚÑEZ, Ma. A. (1994): "La estela funeraria en el mundo andalusí", Actas del V Congreso Internacional de Estelas Funerarias. Soria 28 de abril-1 de mayo de 1993 Soria, pp. 419-444.

MARTÍNEZ NÚÑEZ, Ma. A. (1997): "Escritura árabe ornamental y epigrafía andalusí”, Arqueología y territorio medieval. 4, pp. 127-162.

MARTÍNEZ NÚÑEZ, Ma. A. (1997): "Epigrafía y propaganda almohades”, Al-Qanțara. 18.2, pp. 415-445.

MARTÍNEZ NÚÑEZ, Ma. A. (2007): Epigrafía árabe. Catálogo del Gabinete de Antigüedades. Real Academia de la Historia. Madrid, Real Academia de la Historia (con la colaboración de Isabel Rodríguez Casanova y Alberto Canto García) 
MARTÍNEZ NÚÑ̃EZ, Ma. A. (2014): "Las inscripciones árabes del mihrāb de Vélezmálaga (provincia de Málaga)", Miscelánea de Estudios Árabes y Hebraicos. Sección Árabe-Islam. 63, pp. 143-170.

MEUNIÉ, J.; TERRASSE, H.; DEVERDUN, G. (1957): Nouvelles recherches archéologiques à Marrakech. La coupole almoravide de Marrakech. Paris, Institut des Hautes Études Marocaines.

OCAÑA JIMÉNEZ, M. (1946): "Una mqābriyya almohade malagueña del año $1221 \mathrm{~J}$. C." y "Nuevos datos sobre la mqābriyya almohade malagueña del año $1221 \mathrm{~J}$. C.", Al-Andalus. 11, pp. 224-230 y 445-446.

OCAÑA JIMÉNEZ, M. (1964): Repertorio de inscripciones árabes de Almería. Madrid - Granada, Consejo Superior de Investigaciones Científicas.

OCAÑA JIMÉNEZ, M. (1990): "Panorámica sobre el arte almohade en España", Cuadernos de la Alhambra. 26, pp. 91-111.

OLIVA, D.; GÁLVEZ, M. a E.; VALENCIA, R. (1985): "Fondos epigráficos del Museo Arqueológico de Sevilla", Al-Qantara. 6, pp. 451- 467.

OSMA, G. J. de (1906): "Los letreros ornamentales en la cerámica morisca española del siglo XV", Cultura Española. 46.2, pp. 473-483.

PAVÓN MALDONADO, B. (1966): "Las columnas califales de la Colegiata de Torrijos", Al-Andalus. 31.2, pp. 363-372.

PAVÓN MALDONADO, B. (1967): "Arqueología musulmana en Cáceres (Aljibes medievales)”, Al-Andalus. 32.1, pp. 161-220.

PAVÓN MALDONADO, B. (1968): "Estudio arqueológico de nuevos capiteles califales y dos lápidas granadinas descubiertas en Torrijos", Al-Andalus. 33.2, pp. 435-444.

PAVÓN MALDONADO, B. (1980): "De nuevo sobre Ronda musulmana", Awrāq. 3, pp. 131-174.

PAVÓN MALDONADO, B. (1993): Ciudades y fortalezas lusomusulmanas. Madrid, Agencia Española de Cooperación Internacional.

PÉREZ ÁlVAREZ, Ma. A. (1992): Fuentes árabes de Extremadura. Cáceres, Universidad de Extremadura.

PUERTA VÍLCHEZ, J. M. (2010): Leer la Alhambra. Guía visual del Monumento a través de sus inscripciones. Granada, Patronato de la Alhambra y Generalife.

RAMOS RUBIO, J.A.; DÍAZ ESTEBAN, F. (2005): "Nueva lápida árabe de Trujillo", Anaquel de Estudios Árabes. 16, pp. 201-204.
REVILLA VIELVA, R. (1924): "La colección de epígrafes y epitafios árabes del Museo Arqueológico Nacional", Revista de Archivos, Bibliotecas y Museos (3a época). 45, pp. 228-243 y 2 lám.

REVILLA VIELVA, R. (1932): Patio Árabe del Museo Arqueológico Nacional. Catálogo Descriptivo. Madrid, Museo Arqueológico Nacional.

RODRÍGUEZ AGUILERA, A.; MARTíNEZ ENAMORADO, V. (2012): "Lápidas funerarias árabes procedentes de Hișn Lukk / Luque (Córdoba)”, ANTIQVITAS. 24, pp. 265-276.

ROSSELLÓ-BORDOY, G. (1975): Corpus balear de epigrafía árabe. Palma de Mallorca.

RUBIERA MATA, Ma. J. (1970): “Los poemas epigráficos de Ibn al-Ŷayyāb en la Alhambra”, Al-Andalus. 35.2, pp. 453-473.

RUIZ GIL, J.A.; VALDÉS FERNÁNDEZ, F. (1986-7): "Una supuesta mqabriya del Puerto de Santa María (Cádiz)", Cuadernos de Prehistoria y Arqueología. 13-14, pp. 291298

TOMASSETTI GUERRA, J.M.; JIMÉNEZ-CAMINO ÁLVAREZ, R.; FERNÁNDEZ GALLEGO, C.; BRAVO JIMÉNEZ, S.; NAVARRO LUENGO, I.; SUÁREZ PADILLA, J. (2005): "El cementerio islámico del Fuerte de Santiago (Algeciras, Cádiz). Nuevas excavaciones y síntesis interpretativa", Boletín de Arqueología Yazirí. 1, pp. 96-122.

TORREMOCHA SILVA, A.; MARTÍNEZ ENAMORADO, V. (2004): "Estelas funerarias de época meriní halladas en Algeciras (Cádiz)", Actas del VII Congreso Internacional de Estelas Funerarias. Santander, 24-26 de octubre 2002. Santander, Fundación Marcelino Botín, III, pp. 807-838.

TORRES BALBÁS, L. (1957): "Cementerios hispanomusulmanes”, Al-Andalus. 22.1, pp. 131-191.

VAQUERO, L. (1993): “Colección Gabriel y Galán”, De Gabinete a Museo. Tres siglos de Historia. Museo Arqueológico Nacional, abril-junio de 1993. Madrid, Ministerio de Cultura, pp. 470-471.

W.AA. (1995): Estudios sobre cementerios islámicos andalusies. Málaga, Universidad de Málaga.

W.AA. (2012): Biblioteca de Al-Andalus. Almería, Fundación Ibn Țufayl.

VÍLCHEZ VÍLCHEZ, C. (1988): "La tipología decorativa de las lapidas tabulares y bordillos de sepultura anepigráficos en piedra en la Granada nazarí", Estudios dedicados a D. Jesús Bermúdez Pareja. Granada, Asociacion Cultural de Amigos del Museo Hispanomusulmán, pp. 163-188. 